\title{
Fathers’ Feelings and Experiences during Pregnancy and Childbirth: A Qualitative Study
}

\author{
Anette Ekström ${ }^{1}$, Kristina Arvidsson ${ }^{2}$, Malin Falkenström² ${ }^{2}$ and Stina Thorstensson ${ }^{1 *}$
}

${ }^{1}$ School of Life Sciences, University of Skövde, Sweden

${ }^{2}$ Department of Obstetrics and Gynaecology, Karlskoga Hospital, Sweden

\section{Abstract}

Background: Fathers feel excluded and insecure during childbirth and professional support for fathers can be inadequate. Therefore it is important to further understand fathers experience in order to develop professional support and to create a positive childbirth experience for both fathers and their partners.

Aim: The aim of this study was to explore fathers' feelings and experiences during pregnancy and childbirth.

Materials and Methods: A qualitative method was used, with written interviews which were analyzed using a qualitative content analysis. Participants were eight fathers who wrote answers to two open questions.

Results: The theme "Fathers have strong, mixed feeling while striving to become prepared and to participate during pregnancy and childbirth" crossed over into all the four categories: Being prepared gave security, Feeling needed, Feeling strong, mixed feelings during pregnancy, and Feeling strong, mixed feelings during childbirth. Fathers' previous experiences from childbirth facilitated being prepared and increased sense of security.

Conclusion: It was important for fathers to be prepared and to feel needed and to witness the birth of their baby was fantastic. Overall, the fathers were faced with handling their strong but mixed feelings while striving to prepare for and participate in pregnancy and childbirth.

Implications: Healthcare professionals need to acknowledge that fathers have needs of their own during pregnancy and childbirth. Fathers also worry about the woman and the baby so they need explanations about normal changes as well as possible complications.

Keywords: Father; Feelings; Midwife; Caregivers; Childbirth; Professional support; Expectation; Experience

\section{Introduction}

During pregnancy, fathers express uncertainty and exclusion [1] which is more prominent in first-time fathers [1-3], while fathers with own previous experience of childbirth seem to feel more relaxed [2]. If fathers feeling uncertainty and exclusion they tend to focus on the practical preparations instead of the emotional [1]. Studies describe fathers preparing for childbirth as reading books, participating in antenatal care visits and engaging in dialogue with friends and their partners [4,5]. If the antenatal midwife fails to involve the fathers during care visits, they may feel frustrated and unprepared for childbirth [2]. Expectant fathers desire a dialogue about the practical preparations, as well as parenthood [6]. Fathers expect to be present during childbirth and support their partner [7] and describe their presence during childbirth as non-optional [8]. Being present during childbirth is also an important part of the process of becoming a father [3]. During childbirth fathers' feelings oscillate between euphoria and anxiety $[3,9]$. They express worry for the safety of both their partners and babies [5], as well as feelings of stress, fear and guilt [7]. Fathers describe feelings of being unprepared for the long wait in time, pain and their partners' reactions, as well as their own feelings of helplessness during childbirth $[5,9,10]$. However, cooperation between the midwife and the father in support of the woman could reduce the father's feelings of helplessness [9,11-13].

Healthcare professionals who offer professional support such as, reassurance and continuous information, are important for fathers during their childbirth experiences $[1,2,4,9,11,12]$, but fathers too often describe that professional support can be inadequate $[4,5,11,12,14,15]$. Fathers' positive experience during childbirth is of importance since it will enable his support of the woman $[9,11,13]$. In order to develop professional support and to create a positive childbirth experience for both fathers and their partners it is meaningful to further understand and to develop our knowledge about both first-time and experienced fathers' experiences. The aim of this study was to explore fathers' feelings and experiences during pregnancy and childbirth

\section{Material and Methods}

A qualitative inductive approach was suitable to fulfill the aim of this study, because the direct voices of the fathers provided information about their meaningful values and life experiences. Written interviews were collected using a purposive sampling technique [16]. When using written interviews a pilot test is required [17] and therefore a pilot test was performed. No amendments were made based on the results of the pilot test. The data was analyzed using a qualitative content analysis [18]

The study was performed in two different maternity wards in the central area of Sweden during the autumn of 2012. A purposive sample of fathers [16] based on variations in age, ethnicity and educational level was pursued, and both first-time and experienced fathers (= in this study = own experience of becoming a father, in previous childbirth) were invited to participate, provided they understood and spoke Swedish. Fathers with babies in need for neonatal care were also

${ }^{*}$ Corresponding author: Stina Thorstensson, School of Life Sciences, University of Skövde, PO Box 408, SE-54128 Sweden, E-mail: stina.thorstensson@his.se

Received August 19, 2013; Accepted September 30, 2013; Published October 04, 2013

Citation: Ekström A, Arvidsson K, Falkenström M, Thorstensson S (2013) Fathers' Feelings and Experiences during Pregnancy and Childbirth: A Qualitative Study. J Nurs Care 2: 136. doi:10.4172/2167-1168.1000136

Copyright: (c) 2013 Ekström A, et al. This is an open-access article distributed under the terms of the Creative Commons Attribution License, which permits unrestricted use, distribution, and reproduction in any medium, provided the original author and source are credited. 
invited to participate if they were encountered at the maternity ward. Fathers with babies who had serious diseases were excluded. Access to participants was granted through the midwives at the maternity ward who offered information about fathers who could be included in the study. From this information, the authors (KA or MF) approached eligible fathers, offering them both written and oral information and inquired if they wanted to participate. When using written interviews a pilot test is required [17]. In the pilot test of this study three newly become fathers answered the questions to test their usability, and no amendments were required. The two questions posed were: 1) Describe your thoughts and feelings before childbirth and 2) Describe your experience from childbirth (independently of their partners' experience). Background data such as age, educational level, country of birth and number of children were collected together with the interviews. In total, twenty-five fathers were approached and twenty of them agreed to participate. Of these twenty, five returned the written interview. To assure high confidentiality the returning answers were anonymous so it was not possible to send a reminder to those who did not return the interview. Therefore, to increase data for analysis, the three pilot interviews were included. In total eight fathers were included in the study varying in age from 30 to 36 years of age and in education; five had university education and three had secondary school, five were first-time fathers and three were experienced fathers.

Data from the written interviews were transcribed and analyzed using a qualitative content analysis [18]. In short, the transcripts from the fathers were read through several times, discussed, compared, and validated by all authors. Words and sentences relevant to the research questions were identified as meaning units, which were then condensed and coded. The codes were grouped under subcategories and then organized into categories. Data were further analyzed by reading across the categories, searching for new associations and meanings in the data. In the final step, results were discussed and reflected upon. At the end of the analytical process, a theme that illuminated the results emerged. An example of the analytical process is shown in Table 1.

\section{Ethical considerations}

The ethical principles of the Helsinki declaration [19] guided the study, but according to the Ethical Review Board, no ethical approval was needed for this kind of study in Sweden [20]. The clinical head of service for the hospitals gave access to undertake this study at the hospitals. The fathers were given both written and verbal information about the study. This information also explained that their participation was voluntary and that they could withdraw from the study at any time without having to provide a reason. Returning their written interview was considered as written consent to participate in the study. Confidential handling of all data protected the father's identities. The results are partly expressed by using anonymous quotations to protect the speakers' identities. When asking about experiences from pregnancy and childbirth unexpected feelings could arise in participants. However in Sweden within the healthcare system, access to psychological support is available for all parents, when needed, regardless of participation in research studies or not.

\section{Results}

An overview of the results of this study is shown in Table 2 .

\section{Being prepared gave security}

According to the fathers, an important part of being prepared was about practical preparations. The fathers expected life to change and they understood that there were many practical things to arrange

\begin{tabular}{|c|c|c|}
\hline Meaning unit & Code & Category \\
\hline $\begin{array}{c}\text { I was calm and thought I was helpful. } \\
\begin{array}{c}\text { One does as good as possible to be } \\
\text { supportive and helping .... }\end{array}\end{array}$ & Be there for the woman & Feeling needed \\
My role as supporter felt good & & \\
\hline
\end{tabular}

Table 1: Example of the analytical process.

\begin{tabular}{|c|c|}
\hline Main categories and subcategories & Theme \\
\hline Being prepared gave security & \multirow{4}{*}{$\begin{array}{c}\text { Fathers have strong, mixed feeling } \\
\text { while striving to become prepared } \\
\text { and to participate during pregnancy } \\
\text { and childbirth }\end{array}$} \\
\hline - Feeling needed & \\
\hline $\begin{array}{l}\text { Having strong, mixed feelings during } \\
\text { pregnancy } \\
\text { - feeling desire, excitement and joy } \\
\text { - feeling fear, frustration and uncertainty }\end{array}$ & \\
\hline $\begin{array}{l}\text { Having strong, mixed feelings during } \\
\text { childbirth } \\
\text { - feeling frustration, joy and unreality } \\
\text { - feeling secure despite worry and } \\
\text { powerlessness }\end{array}$ & \\
\hline
\end{tabular}

Table 2: Overview of theme, main categories and subcategories.

before childbirth. Once these preparations were completed, a sense of being prepared to welcome the baby arose, which gave a sense of security.

"I felt pressure to fix all practical stuff such as larger apartment, car and so on."

Being prepared could mean that the fathers did not devote as much attention to reflections on how childbirth would be like, since it was unnecessary to put energy into something they could not possibly control. Being prepared was strengthened by information obtained from friends, the midwife at the antenatal clinic and parental education meetings. These sources of information gave an understanding of what to expect from childbirth and the time afterward. However, the situation was described as abstract and unreal, despite nine months of preparation. They found it difficult to prepare for the birth of a first child and were unclear about what to expect.

"Despite all information from the profylax course it was not possible to understand in what order everything would happen, that is transition between the different stages."

Experienced fathers found it easier to adapt to changes in their lives that came with the birth of a child. Earlier experiences from both childbirth and the healthcare facilities enhanced the feelings of being prepared, which gave a sense of security.

"My feelings and thoughts during pregnancy were significantly calmer this time than with our first child."

\section{Feeling needed}

Feeling needed meant that the fathers believed that they had an important part to play during pregnancy and childbirth. They realized that to offer support by helping their partner physically or strengthening her mentally during childbirth was important for her well-being, so the fathers understood this to be an important task.

"Even to focus on motivation for my wife, from many I have heard that they want to leave right in the middle of everything, to pack up and go home, I saw it as a challenge that we would not end up there."

Feeling needed highlighted a great commitment and a wish to participate during childbirth. To have tasks to perform, for example, to wipe the woman's forehead or bring her a drink, facilitated their sense of participation and strengthened their feelings of being needed. 
It was also described that the midwives at the delivery ward could directly affect the fathers' experiences of feeling needed. They described their needs for confirmation and reassurance from the staff that they were important and were doing a good job. They emphasized that they acknowledged when the midwives were sensitive and saw them as a resource, and to be seen, confirmed and reassured strengthened their feeling of being needed.

"The staff was incredible and gave us fathers' lots of space to help out with whatever we could do."

\section{Having strong mixed feelings during pregnancy}

Feeling desire, excitement and joy: The fathers had strong feelings during the pregnancy, and expecting a baby became their primary focus in life. Becoming a father meant great joy, excitement and expectations, and a strong longing for the baby. It was described as the greatest event of their lives.

"The feeling of being part of something great made me disconnect from almost everything else."

Experienced fathers described feelings of pride in giving a sibling to the first child. According to the fathers, this meant strong feelings of being able to live up to the expectations that they had for themselves.

Feeling fear, frustration and insecurity: The fathers described that if their partner felt sick during pregnancy, they themselves felt empathy and frustration. It was difficult for them to endure standing by while their partner had difficulties with the pregnancy.

"I felt compassion for my partner who felt sick during the entire pregnancy."

The fathers described that they were frustrated about the length of the pregnancy and that time passed slowly. Above all, passing the expected date was distressing and increased their frustration.

"Time couldn't pass quickly enough for me."

The pregnancy imposed changes in the relationships and they often became unequal. The fathers had to take more responsibility for the chores at home and they felt frustrated when this affected their work.

One strong feeling that was described was fear, and the fathers revealed fear that their babies would be or become ill, and fear of what may happen if the baby was malformed or ill. If their partner was ill during pregnancy, the fathers feared that the health of the baby might be affected. They also described fears for the act of childbirth itself and possible complications, even if they tried not to think about it.

"I had some waking nightmares about what it might mean for my partner to give birth."

The lack of control over when and where the childbirth would start created insecurity, and the fathers felt excluded and dependent on information from their partners. The thought of not arriving at the delivery ward in time, and having to deliver the baby themselves was described as a feeling of insecurity. This sometimes imposed feelings of doubt about their own abilities and insecurity about their new roles.

"Thoughts about childbirth were often about uncertainty of when it would begin."

\section{Having strong, mixed feelings during childbirth}

Feeling frustration, joy and unreality: During childbirth the fathers described strong but mixed feelings, and they had difficulty putting the strong feelings circulating through their bodies into words.
Witnessing the birth of their baby was described as a fantastic, joyful experience, and that it was not possible to be prepared for something as great as that. To them it felt both unreal and unique.

"Just to be present when a new individual comes into this world. Great!"

The process of childbirth was described as smoother than expected, and experienced fathers described that it was quicker the second time. However, if the childbirth was prolonged and no one could give an accurate prediction of time, the fathers got frustrated.

"...she was in bed and rested as much as she could - (I) have an understanding for that but it was really boring."

Feeling secure despite worry and powerlessness: A sense of worry arose when the fathers were with a partner who was in pain. They described the wish to do more and to be able to take part of the pain. The fathers described that this situation created a feeling of powerlessness and of being lonely and excluded.

"One feels so alone since one is accustomed to being a team but one player is missing."

Despite the feelings of worry and powerlessness during childbirth, the fathers felt safe, and they described a feeling of being taken care of by competent healthcare professionals. The fathers explained that cooperation with the midwife was positive and that they had full confidence in the healthcare professionals. After their babies were born, a sense of relief arose in the fathers because their fears did not become reality. This made the fathers relax and rejoice over their newly born babies.

\section{Fathers have strong, mixed feelings while striving to become prepared and to participate during pregnancy and childbirth}

The fathers described strong but mixed feelings during pregnancy and childbirth. Positive feelings such as excitement and joy were mixed with negative feelings such as fear, worry and loneliness. The fathers faced these strong, mixed feeling at the same time as they were striving to become prepared to meet the challenges of parenthood and of participating and supporting the woman during pregnancy and childbirth. The fathers felt excited, they felt empathy and consideration for their partners, and they wanted to participate. However, they sometimes felt excluded and lonely during pregnancy and childbirth. Support from healthcare professionals was important for the fathers to be able to handle their feelings and to act supportive to the woman during pregnancy and childbirth.

\section{Discussion}

The fathers in this study described strong, mixed feelings both during pregnancy and childbirth. They wanted to participate during pregnancy and childbirth, but, the fathers sometimes experienced being excluded and lonely when healthcare professionals did not take the fathers role and participation as important. However, healthcare professionals offering individual support enabled fathers to be prepared which increased the fathers' involvement and support to the woman. The fathers felt needed and saw that they had important tasks to perform, and if the healthcare professionals reassured the fathers, their feelings of being needed increased.

Being prepared was facilitated by mediated information during pregnancy, which increased the fathers' sense of security. The fathers described a pre-understanding of childbirth gained by information from antenatal care visits, parental education meetings and dialogue with friends; however, they found that it was hard to anticipate what 
was expected of them. Research points to the fathers after childbirth describing a feeling of being unprepared for the intensity of the childbirth process, despite having previous information [5]. In order to increase the fathers' feelings of being prepared it is important to involve them during pregnancy [11]. In line with our results it is evident that healthcare professionals have an important role in including and educating expecting fathers to increase their feeling of being prepared. Parental education meetings should include relevant, clear and individually adapted information which is directly aimed at expecting fathers. Ekström et al. [21] point out that improved professional support during pregnancy influence mothers' parental role in a positive way after birth.

To be prepared also included fathers' practical preparations during pregnancy and being prepared contributed to a sense of security, despite the first-time fathers uncertainty of what to expect from childbirth. This is in line with earlier research that describes uncertainty about what to expect of first-time fathers, while experienced fathers felt more at ease [2,3]. Experienced fathers exhibited less fear before childbirth than first-time fathers [22]. This would indicate that experienced fathers over-all are calmer than first-time fathers. However, it is important to point out that experienced fathers may have had negative experiences from earlier childbirth and healthcare professionals should therefore offer individually adapted support and not assume that experienced fathers feel secure. Premberg and Lundgren [23] show that to provide childbirth education for both parents, it is necessary to develop a new model for childbirth education that is better suited to both sexes. The expectant fathers should obtain tools to offer support to women during pregnancy and childbirth and to be better prepared for the parenthood [23].

Overall, the fathers felt needed both during pregnancy and childbirth, when they understood that they had tasks to perform that were important for their partners. The fathers described that cooperation with healthcare professionals could contribute to their feeling of being needed, and it was important for them to be seen, reassured and acknowledged by the healthcare professionals. Earlier research confirms that the active cooperation between midwives and partners creates a sense of participation and confirms the father's importance during childbirth $[9,12,13]$. These are significant results, pointing to an important role for healthcare professionals who can contribute to a positive childbirth experience for fathers, but also aid them in offering support to their partners.

In our results the relationship was described as becoming more unequal during pregnancy, since the fathers felt they were forced to take more responsibility for household shores. These results of fathers' experiences during pregnancy demonstrate a new perspective since earlier research has mainly focused on the relationship after childbirth [24]. Changes in the relationship when expecting a baby is important to illuminate, as well as to further explore the consequences these changes may have.

Fathers described strong, mixed feelings during pregnancy. If their partner had difficulties during pregnancy, the fathers described feelings of empathy as well as frustrations over the length of the pregnancy. They also described feelings of fear and worry about complications during childbirth. This is in line with earlier research that fathers express worry for their partners and babies during pregnancy and childbirth $[5,8,9,14]$, as well as compassion for a partner with difficulties during pregnancy [2]. These research results and our results indicate that fathers worry about their partners' health and suffer with them. Hence it is important that healthcare professionals are alert and responsive to signals from fathers when their partners describe feeling unwell during pregnancy and childbirth. However, earlier research point out that fathers do not want healthcare professionals to meet their needs if that mean neglecting the needs of the women [3].

In this study the fathers describe uncertainty toward the onset of childbirth which created a sense of lack of control with the fathers. They felt excluded and dependent on information from their partner, and the thought of not arriving at the delivery ward in time created uncertainty. The results of Chandler and Field [10] contradict these results and state that the fathers felt secure before childbirth, and that the decision about when to leave for the delivery ward was made in cooperation with the partner. However, other studies [1,9] confirmed our results of fathers feeling excluded, stressed and insecure before childbirth. It could become strenuous for the relationship if the fathers feel excluded since it can create an imbalance. This could be important for healthcare professionals to acknowledge and prevent.

The fathers described having strong, mixed feelings also during childbirth. They felt uncertain, powerless and lonely. The fathers wanted to be able to do more in relation to the woman, to take part of her pain. Especially when labor was prolonged the fathers described feeling frustrated which may be due to their helplessness to relieve her pain. Research shows that a father's sense of helplessness increases when the delivery is prolonged [10], while the presence of a midwife will decrease the father's sense of helplessness and increase his sense of security during childbirth $[11,12]$. A more secure father may increase the chances of a more secure woman, which could facilitate childbirth and create a positive childbirth experience. The woman's sense of security is important to create a positive childbirth experience for her $[25,26]$.

Despite feelings of worry and powerlessness, the fathers in this study described feelings of security and confidence in the competence of the healthcare professionals. Earlier research describes that support and encouragement of healthcare professionals have an impact on the experiences of the fathers $[9,12,13]$. This would indicate the importance of healthcare professionals in actively creating an atmosphere of security, to decrease that fathers have feelings such as powerlessness or fear. It is possible that the healthcare professionals perceive the childbirth process as normal, but fail to communicate this to the father who might experience childbirth as lasting "forever". Healthcare professionals should reflect on fathers not having the knowledge about the normal length of the childbirth process, and it is important to confirm the normality to them. Informative support encourages the coping capacity for individuals in stressed situations [27], however, the ability to offer support is affected by the healthcare professional's attitudes and ideological ideas about support [13].

The fathers in this study found it hard to articulate the strong feelings they experienced, however childbirth was described as a fantastic experience, and once the baby was born feelings of relief were described. One earlier study describes the birth of a child as an overwhelming experience for the fathers, and feelings vary between happiness and despair [9]. However, the results of another study only describe the positive feelings of the fathers during childbirth [3]. This would indicate the importance for further research on the fathers' experiences, as well as the importance for healthcare professionals to anticipate many different kinds of strong feelings and to show respect for different ways of expressing these feeling in fathers.

A qualitative design with content analysis was used in this study to explore fathers' experiences and feelings. The content of the written interviews depended on the fathers' capability to express themselves in words. This method gave a wide variation of descriptions, and the 
fathers described their own experiences without any interference from the authors. This data collection method contributed to the richness of the data for analysis and to fulfill the aim of the study. Using written interviews was unique since other qualitative studies involving fathers used interviews, which mean that our results also strengthen earlier results through different data collection methods [28]. One limitation of this study was that access to participants was granted through the midwives at the maternity wards who provided information about suitable fathers to include in the study. These midwives could have had inclusion or exclusion criteria of their own, unknown to the authors of this study, which could have affected which fathers were invited to participate. Of the twenty fathers who agreed to participate only five returned their written interviews. It is not possible to know why so many fathers did not return their written interviews but the first time at home after a baby has been born has been described as a challenge [24,29]. It is possible that the fathers not returning their interviews did not find the time or the strength to write down their experiences. In order to strengthen the results, data from the pilot study was included in the analysis since the questions posed in the pilot study did not differ from the main study. However, using written interviews with no possibility of a reminder must be considered a limitation while being able to give participating fathers high confidentiality must be considered strengthening of the study. This study is also limited by its small sample size, but the context and participating fathers are described as clearly as possible to facilitate the transferability of the results $[18,27]$. The fathers that were invited to participate were in line with the purposive sampling strategy [28], and in order to gain a rich data set, only two open questions were used [17] which could be considered strength of the study.

\section{Conclusion}

It is important for fathers to be prepared and to feel needed, which could be improved by professional support from healthcare professionals. Fathers need to be acknowledged, seen and encouraged by healthcare professionals. Strong, mixed feelings were described during pregnancy and childbirth. It was difficult for fathers to articulate their strong feelings, however witnessing the birth of their babies was described as a fantastic and joyful experience. Overall, the fathers were faced with handling strong, mixed feelings while striving to prepare and participate during pregnancy and childbirth

\section{Clinical implications}

Results of this study indicate the importance for healthcare professionals to acknowledge fathers' own experiences and needs during pregnancy and childbirth. However, fathers also worry about the woman and the baby. Therefore healthcare professionals need to meet the fathers worry and explain normal changes as well as if complications arise during pregnancy and childbirth. If fathers are not acknowledged by healthcare professionals their feelings of frustration, helplessness, loneliness and worry may increase, which negatively contribute to their experience. When fathers' experiences are more positive their capacity to support the woman will increase, which may contribute positively to the woman's childbirth experience as well as to their parental role development.

\section{References}

1. Longworth HL, Kingdon CK (2011) Fathers in the birth room: what are they expecting and experiencing? A phenomenological study. Midwifery 27: 588594.

2. Fenwick J, Bayes S, Johansson M (2012) A qualitative investigation into the pregnancy experiences and childbirth expectations of Australian fathers-to-be. Sex Reprod Healthc 3: 3-9.
3. Vehviläinen-Julkunen K, Liukkonen A (1998) Fathers' experiences of childbirth Midwifery 14: 10-17.

4. Bäckström C, Hertfelt Wahn E (2011) Support during labour: first-time fathers' descriptions of requested and received support during the birth of their child Midwifery 27: 67-73.

5. Hallgren A, Kihlgren M, Forslin L, Norberg A (1999) Swedish fathers' involvemen in and experiences of childbirth preparation and childbirth. Midwifery 15: 6-15.

6. Chalmers B, Meyer D (1996) What men say about pregnancy, birth and parenthood. J Psychosom Obstet Gynaecol 17: 47-52.

7. Somers-Smith MJ (1999) A place for the partner? Expectations and experiences of support during childbirth. Midwifery 15: 101-108.

8. Eriksson C, Salander P, Hamberg K (2007) Men's experiences of intense fear related to childbirth investigated in a Swedish qualitative study. The journal of men's health \& gender 4: 409-418.

9. Premberg Å, Carlsson G, Hellström AL, Berg M (2011) First-time fathers' experiences of childbirth--a phenomenological study. Midwifery 27: 848-853.

10. Chandler S, Field PA (1997) Becoming a father. First-time fathers' experience of labor and delivery. J Nurse Midwifery 42: 17-24.

11. Sapkota S, Kobayashi T, Takase M (2012) Husbands' experiences of supporting their wives during childbirth in Nepal. Midwifery 28: 45-51.

12. Thorstensson S, Ekström A, Lundgren I, Hertfelt Wahn E (2012) Exploring Professional Support Offered by Midwives during Labour: An Observation and Interview Study. Nurs Res Pract 2012: 648405.

13. http://oru.diva-portal.org/smash/get/diva2:512828/FULLTEXT02.pdf

14. Shibli-Kometiani M, Brown AM (2012) Fathers' experiences accompanying labour and birth. British Journal of Midwifery 20: 339-344.

15. Hildingsson I, Cederlöf L, Widén S (2011) Fathers' birth experience in relation to midwifery care. Women Birth 24: 129-136.

16. Polit D, Beck CT (2011) Nursing Research. Generating and Assessing Evidence for Nursing Practice. (9thedn), Lippincott Williams and Wilkins.

17. Gillham B (2008) Forskningsintervjun: Tekniker och genomförande (Researchinterviews; technique and implementation). Studentlitteratur.

18. Graneheim UH, Lundman B (2004) Qualitative content analysis in nursing research: concepts, procedures and measures to achieve trustworthiness. Nurse Educ Today 24: 105-112.

19. World Medical Association (2002) World Medical Association Declaration of Helsinki: ethical principles for medical research involving human subjects. $J$ Postgrad Med 48: 206-208.

20. http://www.epn.se/en/start/startpage/

21. Ekström A, Guttke K, Lenz M, Hertfelt-Wahn E (2011) Long term effects of professional breastfeeding support - An intervention. International Journal of Nursing and Midwifery 3: 109-117.

22. Johansson M, Rubertsson C, Rådestad I, Hildingsson I (2012) Childbirth - an emotionally demanding experience for fathers. Sex Reprod Healthc 3: 11-20.

23. Premberg Å, Lundgren I (2006) Fathers' experiences of childbirth education. J of Perinatal education 15: 21-28.

24. Cowan CP, Cowan PA (2000) When partners become parents. The big life change for couples, Lawrence Erlbaum Associates, USA

25. Lundgren I, Karlsdottir S, Bondas T (2009) Long-term memories and experience of childbirth in a Nordic context - a secondary analysis. International Journal of Qualitative Studies on Health and Well-being 4: 115-128.

26. Nilsson L, Thorsell T, Zandren Hammar P, Pethrus P, Ekström A (2012) Most important for first time mothers durin labor is to be respected for their needs, to feel involved in the care and support from their partners. Journal of Nursing \& Care 1.

27. Langford CP, Bowsher J, Maloney JP, Lillis PP (1997) Social support: a conceptual analysis. J Adv Nurs 25: 95-100.

28. Patton MQ (2002) Qualitative research and evaluation methods. (3rdedn), Thousand Oaks, Sage Publications inc, California

29. Mercer RT (2004) Becoming a mother versus maternal role attainment. J Nurs Scholarsh 36: 226-232. 